\title{
Metodología y desarrollo de la auditoría forense en la detección del fraude contable en Colombia
}

\author{
Methodology and Development of the Forensic Audit on Detecting Accounting Fraud in Colombia \\ Méthodologie et développement de l'audit légal pour la détection de fraude comptable en Colombie
}

\begin{abstract}
Maricela Ramírez
Docente investigadora, Universidad de Boyacá, Tunja - Colombia. Coordinadora de Semillero INDECONT. Magister en Administración Económica y Financiera. Especialista en Revisoría Fiscal.

Contadora Pública.

E-mail: mramirez@uniboyaca.edu.co
\end{abstract}

Johana Reina Bohórquez Contadora Pública, Universidad de Boyacá, Tunja - Colombia. Integrante fundadora de Semillero INDECONT. E-mail: bjreina@uniboyaca.edu.co

Artículo de investigación científica y tecnológica Según clasificación COLCIENCIAS

Recepción: 06/03/2013

Corrección: 06/05/2013

Aprobación: 11/11/2013

\section{Resumen}

Al contador público le corresponde actuar como auditor forense en los procesos judiciales adelantados por delitos económicos y financieros como profesional "auxiliar de la justicia en los casos que señala la Ley, como perito expresamente designado para ello" (Congreso de la República, 1990). El presente documento compila los referentes normativos, procedimientos y metodología que el contador público en Colombia requiere emplear en la recopilación, divulgación y atestación de la evidencia válida y suficiente en la detección del fraude contable, desde cuatro fases específicas: (1) planeación, (2) elaboración y desarrollo, (3) comunicación de resultados y (4) monitoreo. En cada una de estas etapas, las normas internacionales de auditoría, el código penal, el código de procedimiento civil, el código de procedimiento penal y los lineamientos contables estipulados en la normatividad colombiana son los referentes propicios para la obtención de la evidencia valedera como prueba pericial contable especializada ante los tribunales de la justicia.

Palabras clave: evidencia, fraude, informe pericial, prueba contable especializada, cadena de custodia, normas internacionales de auditoría.

\section{Abstract}

Public accountants can act as forensic auditors in judicial processes carried out by economic and financial crimes as "a judicial officer in cases indicated by the law, or as an expert witness expressly designated for such"(Congress of the Republic of Colombia, 1990). This document compiles the legal regulations, procedures, and methodology that public accountants in Colombia need to use in collecting, disclosing, and testifying to valid and sufficient evidence detecting accounting fraud, from four specific phases: (1) planning, (2) design and development, (3) communication of results, and (4) monitoring. In each of these stages, international auditing standards, the criminal code, code of civil procedure, criminal procedure code and accounting guidelines stipulated in the Colombian regulations are the suitable references to obtain valid evidence as specialized accounting expert proof in courts of justice.

Keywords: evidence, fraud, expert report, specialized accounting evidence, chain of custody, international auditing standards.

\section{Résumée}

Le comptable public doit agir comme auditeur légal dans les processus judiciaires correspondant à des délits économiques et financiers en tant que professionnel “auxiliaire de la justice pour les cas signalés par la Loi, tel que expert désigné expressément pour cela” (Congrès de la République, 1990). Ce document présente la compilation de référents normatifs, de procédures et de méthodologies que le comptable public doit utiliser en Colombie pour le recueil, la divulgation et l'attestation de l'évidence valide et suffisante pour la détection du fraude comptable depuis quatre phases spécifiques : (1) planification, (2) élaboration et développement, (3) communication des résultats, et (4) contrôle. Dans chaque étape, les normes internationales d’audit, le code pénal, le code de procédure civil, le code de procédure pénal et les lignes directrices comptables stipulées dans la normativité colombienne sont les référents indiqués pour obtenir l'évidence valable en tant que preuve comptable judiciaire spécialisée face aux tribunaux de justice. 


\section{Introducción}

La "contabilidad forense" se encarga de detectar indicios y desenterrar evidencias de fraudes corporativos o actos de corrupción en entes privados o públicos, al revisar los libros contables, los balances y las facturas de una compañía (Saccani, 2010).

Es así como el desarrollo de la auditoría forense entorno al fraude contable, encadena una serie de procedimientos: jurídicos (tipificación del fraude, manejo de la cadena de custodia, informe pericial, evidencia probatoria); de auditoría [normas internacionales de auditoría emitidas por la Federación Internacional de Contadores (IFAC)]; y procedimientos contables (en el caso colombiano, contenidos en el reglamento de contabilidad vigente y en los lineamientos emitidos por los entes de vigilancia y control de cada sector).

La presente investigación busca establecer las reglas, principios, técnicas y métodos suficientes que le permitan al contador público desarrollar el programa de auditoría forense de manera pertinente, eficiente, eficaz y confiable allegando la evidencia concluyente para los casos de fraude contable.

\section{Metodología}

Para identificar las fases de la auditoría forense relacionadas con la detección del fraude contable, se llevó a cabo un estudio descriptivo de los referentes que aportan los estándares internacionales de auditoría versión 2009, las normas nacionales contempladas en el Código de Procedimiento Civil, Código Penal y el Código de Procedimiento Penal en el hallazgo de la prueba pericial contable especializada.

\section{Resultados}

\section{Fases de la auditoría forense}

La auditoría forense investigativa está orientada a identificar la existencia de fraudes mediante una profunda investigación llegando a establecer entre otros aspectos, los siguientes: determinar la cuantía del fraude, efectos directos e indirectos, posible tipificación, presuntos autores, cómplices y encubridores (Fontán, 2009). La auditoría forense se considera mucho más efectiva que la auditoría de los estados financieros en la investigación del fraude contable (Estupiñan, 2006). El fraude contable al ocultar activos, pasivos, ingresos o sobreestimar costos en estados financieros, busca defraudar al Estado, a los accionistas, a los acreedores, pues se logra con ello pagar menos impuestos, distribuir menos dividendos, constituir menores reserva que protejan el patrimonio y las deudas a favor de los acreedores (Bermúdez, 2000).

Históricamente, los contadores forenses, han sido los profesionales llamados a encontrar la evidencia del fraude (Singleton, Bologna y Lindquist, 2006). Se espera que el auditor forense tenga una base fuerte en el manejo contable, acompañados con conocimientos sólidos de auditoría, valoración de riesgos y control; además, debe demostrar un conocimiento del ambiente legal necesario para su trabajo como litigante y tener una serie de habilidades para una ejecución eficiente en su labor como la comunicación, las habilidades de detective y de litigante audaz (Rodríguez, 2009).

\begin{tabular}{|c|}
\hline Figura 1. Conocimientos y habilidades del auditor forense \\
Legal - litigación \\
\hline Auditoría \\
\hline Contable \\
\hline Detective - Criminología - Comunicación \\
\hline Fuente: Rodríguez-Castro $(2009)$.
\end{tabular}

Cabe señalar que el fraude radica en una disimulación u ocultamiento de hechos o en la afirmación de hechos o circunstancias falsas (Chavarria y Roldán, 1996). De esta forma la auditoría forense enmarca cuatro importantes fases (Figura 1); cada una aplicada de manera correcta y eficiente, permite el desarrollo de una auditoría pertinente, eficaz y de resultados, independientemente del fraude contable que se trate.

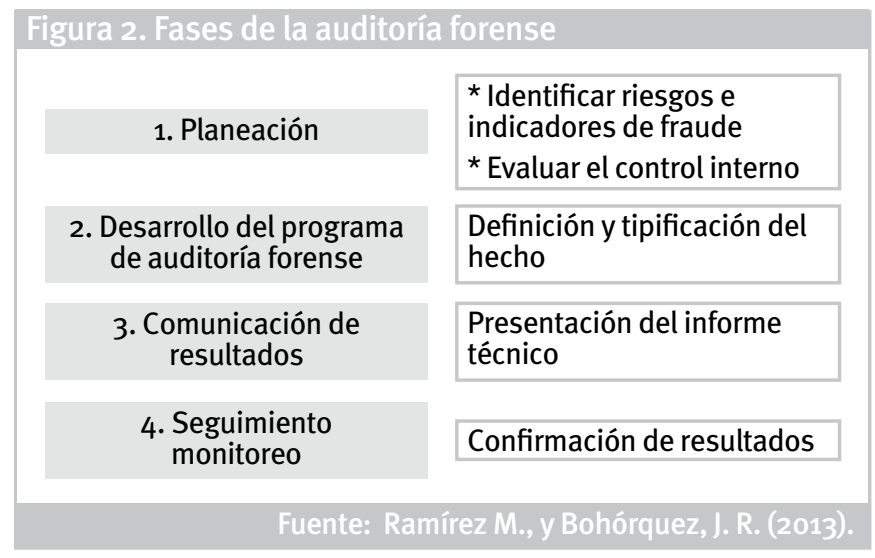

\section{Primera fase: planeación}

Como lo estipulan las normas internacionales de auditoría emitida por la Federación Internacional de Contadores (IFAC), el auditor debe planear la auditoría con una actitud de escepticismo profesional reconociendo que pueden existir circunstancias que causen que los estados financieros estén sustancialmente representados en forma errónea.

Asimismo, estas normas señalan que el trabajo de auditoría debe ser técnicamente planeado para alcanzar los objetivos trazados en la forma más eficiente posible, así lo confirma, la Norma Internacional de Auditoría 300 (IFAC, 2009). De acuerdo con el Código de Procedimiento Civil "la parte que solicite un dictamen pericial determinará concretamente las cuestiones sobre las cuales 
debe versar, sin que sean admisibles puntos de derecho" (Congreso de la República, 2012). Bajo este referente el contador público como auditor forense, planeará su trabajo.

Para el desarrollo de esta primera fase se hace prioritario conocer el negocio, el sector y las variables endógenas y exógenas que envuelven el posible caso de fraude contable, a partir de los siguientes lineamientos:

\section{Entender el negocio NIA 315}

Conocer el caso y el entorno: objeto social, cliente potencial, competencia, acreedores, relaciones financieras, misión, visión, objetivos, planes o metas entre otros (IFAC, 2009) y generando así un expediente documental de antecedentes y situación financiera que puede contener:

Tabla 1. Expediente documental de antecedentes y
situación financiera
Historia general de la empresa desde su constitución.
Copia de estatutos: constitución y reformas.
Certificado de existencia y representación legal.
Copia de permisos de funcionamiento y licencias.
Situación legal en todos los órdenes.
Stakeholders.
Operaciones actuales.
Planes para el futuro.
Estructura para afrontar la globalización.
Contratos a largo plazo.
Estudios actuariales.
Garantías otorgadas.
Títulos de propiedad y sus gravámenes.
Convenios y/o pactos colectivos de trabajo.
Contratos o convenios especiales.
Normatividad y legislación aplicable.
Estados financieros (últimos 5 años).
Indicadores financieros EBITDA, EVA,
TIR, BAll, BDI, entre otros.
Indicadores de industria.
Análisis de viabilidad como empresa en marcha.
Determinación del punto de equilibrio.
Sistema de información financiera y contable, software de
contabilidad.
Calidad de la operación, personal y organización del
departamento de contabilidad.
Estado de los libros oficiales de contabilidad.
Indicadores de riesgo/mapa de riesgo.
Informes y dictámenes de revisor fiscal (5 años).
Informes de gestión (5 años).

De esta manera el auditor cuenta con la información precisa, necesaria y suficiente para dar inicio a la labor de conocimiento del caso investigado.

Identificar riesgos e indicadores de fraude. NIA 320

Esta etapa comprende el estudio, evaluación y proyección de riesgos e indicadores. Estos se pueden agrupar así (IFAC, 2009):
Expediente de riesgos e indicadores de fraude

Personal. Este expediente busca identificar comportamientos inusuales, tales como actos ilegales, estilos de vida costosos, vacaciones no tomadas, personal de baja calidad, empleados trabajando frecuentemente por fuera del horario laboral, remuneración ligada a los resultados financieros, naturaleza y calidad de las utilidades dudosas, segmentos de negocio conocidos por pocos empleados, personas autoritarias que evaden los controles.

Comerciales y financieros. En este expediente los síntomas incluyen: baja moral, alta rotación de los directivos y poco seguimiento y control sobre las metas, crecimiento de las ventas, niveles anormales de rentabilidad que pueden indicar la existencia de transacciones fuera de lo convencional, una estructura de sistemas insuficiente para el volumen y naturaleza de las operaciones de una compañía, utilidades por encima del promedio de la industria, desajuste entre el crecimiento y el desarrollo de los sistemas, reputación pobre, problemas de liquidez, estructuras complejas, el uso de organizaciones "paralelas".

Estructurales. Es importante indagar y registrar los sitios remotos mal supervisados, la búsqueda de resultados a cualquier costo, origen de ingresos sin relación con objeto social, negocios que son complejos de entender y la comunicación entre firmas es mínima, la administración puede envolverse en un nivel tan extremo con el logro de metas financieras $u$ operativas que esto se convierte en un blanco dominante a expensas de la productividad 0 eficiencia a largo plazo.

Culturales. Presentando presiones de sus superiores y del temor a perder el empleo. Con esta actitud, se hacen cómplices involuntarios de eventuales fraudes.

\section{Evaluación del control interno. Factores}

De acuerdo con la seguridad que brinde el control interno de la entidad, se debe organizar y administrar de forma apropiada, el trabajo de auditoría forense de modo que se desempeñe de manera efectiva y eficiente determinando desde el inicio:

Alcance. Se determina mediante un análisis del control interno organizacional que permitirá detectar errores significativos con el fin de alcanzar el grado de oportunidad y de extensión de los procedimientos de auditoría que se aplicarán.

Estrategia. Desarrollar un conjunto de tácticas en auditoría que permita el cumplimiento de los objetivos trazados en el memorando de planeación.

Materialidad (transacciones, hechos significativos). La relación de cada hecho o indicio que pueda ser objeto de investigación y que sirva como prueba para esclarecer los hechos.

Controles TIC. Acceso y revisión de cada una de las tecnologías de información y comunicación (TIC) de las cuales la empresa o el ente en cuestión hayan hecho uso.

Calificación de riesgos en auditoría. Representa la evaluación de la posibilidad de que el auditor exprese 
una opinión errada en su informe debido a que los estados financieros o la información suministrada a él estén afectados por una distorsión material o normativa.

Al finalizar la evaluación de control interno en los papeles de trabajo se debe involucrar el siguiente expediente:

Tabla 2. Expediente resultado de la evaluación del
control interno
Organigrama jerárquico
Mapa de procesos de la empresa
Objetivos y política de la organización
Sistema de información contable
Plan de cuentas y políticas contables
Manual de procedimientos y funciones
Sistema de auditoría interna
Sistema de supervisión y actividades de control, seguimiento y
monitoreo
Matriz de riesgos
Sistema de prevención de riesgos
Sistema de información y comunicación
Sistema de protección de activos, incluido almacenamiento y
manejo de inventarios
Información de la gerencia

\section{Fuente: Régimen Contable Colombiano, 2013}

\section{Segunda fase: elaboración y desarrollo del programa de auditoría forense}

Esta fase se desarrolla en cinco etapas de auditoría, así:

Etapa 1

Definición y tipificación del hecho (tipo de fraude). La Ley 906 de 2004 en Colombia establece que según el daño causado en la sociedad se debe administrar el fraude. La sociedad resulta afectada por este tipo de ilícitos económicos a través de los stakeholders terceros vinculados a las empresas directa o indirectamente.

Cabe señalar que de acuerdo con el derecho penal, se tipifican fallas o irregularidades llamadas fraudes, abuso de confianza, hurto, estafa, fraude mediante cheque. Para esta clase de actuaciones delictivas, el código penal de todos los países los agrupa bajo el epígrafe de "delitos contra el patrimonio económico" (Estupiñan, 2006). En Colombia estos delitos se encuentran contemplados en el Título VII en los Artículos 239 al 269 del Código Penal.

Ahora bien el fraude "es un fenómeno económico, social y organizacional, aplicado a la contabilidad; el fraude consiste en cualquier acto u omisión de un acto de naturaleza dolosa y por tanto de mala fe, o de negligencia grave." (Gil y Rodríguez, 2010). El esquema de fraude cubre malversación de activos, corrupción y falsas representaciones y la manipulación de estados financieros.

Bajo la Norma Internacional de Auditoría 240 "Responsabilidades del auditor en la auditoría de estados financieros con respecto al fraude" el fraude se define como un "acto intencionado realizado por una o más personas de la dirección, los responsables del gobierno de la entidad, los empleados o terceros, que conlleve la utilización del engaño con el fin de conseguir una ventaja injusta o ilegal" (IFAC, 2009).

Asimismo las Normas Internacionales de Auditoría (NIA) 240 trata de las responsabilidades que tiene el auditor con respecto al fraude en la auditoría de estados financieros. En concreto, desarrolla el modo de aplicar la NIA 315 y la NIA 330 en relación con los riesgos de incorrección material debido a fraude.

En este orden de ideas la NIA 240 se convierte en una herramienta que permite identificar los factores de riesgo de fraude como aquellos "hechos o circunstancias que indiquen la existencia de un incentivo o elemento de presión para cometer fraude o que proporcionen una oportunidad para cometerlo" (IFAC, 2009).

\section{Etapa 2}

Recopilación de evidencias. Este procedimiento consiste en allegar los principios de derecho probatorio y analizarlos a la luz de lo dispuesto en las leyes, profundizar en materia de la prueba como elemento que se constituye en una labor de estudio de gran importancia para los investigadores del delito. "La prueba es la forma con la que han contado los funcionarios judiciales, basados en las experiencias personales y en las tendencias ideológicas de la norma jurídica llamada a solucionar el problema suscitado" (Cano y Lugo, 2009).

En la mayoría de los casos se hace necesario el apoyo de profesionales del derecho como expertos que soporten los procedimientos por lo general administrativos y que interpreten jurídicamente las leyes locales e internacionales.

Según las NIA la evidencia se convierte en un elemento necesario en el desarrollo de la investigación; por lo tanto, las NIA 500 respecto a la evidencia, aportan la forma de obtenerla para llegar a conclusiones razonables en las cuales basar la opinión de auditoría, a través, de un análisis y revisión para determinar la consistencia y confiabilidad de los registros contables, hechos y cifras (por ejemplo, se dice que la evidencia es más confiable cuando se obtiene de fuentes externas).

Estas normas igualmente afirman cómo la evidencia obtenida directamente por el auditor por medio de la observación y otros medios, es más confiable que la obtenida de forma indirecta o por inferencia y cuando se soporta en documentos físicos o electróni$\cos u$ otros medios (actas de reuniones). La Figura 2 presenta el aporte que las NIA brindan en la obtención de la evidencia válida y suficiente (IFAC, 2009). 


\begin{tabular}{|c|c|c|}
\hline $\begin{array}{l}\text { NIA 550. Partes relacionadas: La } \\
\text { norma requiere que el auditor } \\
\text { obtenga representaciones adecuadas } \\
\text { de la dirección sobre las partes } \\
\text { relacionadas. }\end{array}$ & $\begin{array}{l}\text { NIA 5oo. Elementos de juicio en la } \\
\text { auditoría: Elementos de juicio válidos } \\
\text { y suficientes (provenientes de los } \\
\text { registros contables y de la } \\
\text { documentación) para sustentar en } \\
\text { forma razonable sus conclusiones. }\end{array}$ & $\begin{array}{l}\text { NIA 545. Auditoría de las mediciones a } \\
\text { valores corrientes y su exposición: } \\
\text { cómo la entidad determina y expone } \\
\text { los valores corrientes, evaluar los } \\
\text { riesgos inherente y de control. }\end{array}$ \\
\hline \multirow{3}{*}{$\begin{array}{l}\text { NIA 501. Elementos de juicio en la } \\
\text { auditoría: La norma proporciona las } \\
\text { guías para el trabajo del auditor } \\
\text { durante el conteo del inventario físico, } \\
\text { los elementos de juicio que debe } \\
\text { reunir. }\end{array}$} & \multirow{3}{*}{$\begin{array}{c}\text { Evidencia } \\
\text { de auditoría }\end{array}$} & \multirow{3}{*}{$\begin{array}{l}\text { NIA 505. Confirmaciones externas: El } \\
\text { auditor determina si el uso de } \\
\text { confirmaciones es necesario para } \\
\text { obtener elementos válidos de juicio } \\
\text { para respaldar las afirmaciones } \\
\text { contenidas en los estados contables. }\end{array}$} \\
\hline & & \\
\hline & & \\
\hline $\begin{array}{l}\text { NIA 56o. Hechos posteriores: } \\
\text { Tratamiento de hechos: ocurridos } \\
\text { hasta la fecha del informe, los } \\
\text { descubiertos después del informe, } \\
\text { descubiertos después que los } \\
\text { estados contables fueron emitidos. }\end{array}$ & $\begin{array}{l}\text { NIA 510. Primera auditoría. Saldos } \\
\text { iniciales: Que no contengan errores } \\
\text { significativos, que los saldos del } \\
\text { ejercicio anterior hayan sido } \\
\text { correctamente trasladados al } \\
\text { presente. }\end{array}$ & $\begin{array}{l}\text { NIA 540. Auditoría de las estimaciones } \\
\text { contables: Revisión que debe seguir } \\
\text { el auditor: el análisis de estimaciones } \\
\text { de la gerencia, la comparación con } \\
\text { elementos independientes que } \\
\text { confirmen la estimación efectuada y } \\
\text { la evaluación de los resultados. }\end{array}$ \\
\hline
\end{tabular}

En este momento es importante señalar la diferencia existente entre la evidencia y la prueba en términos legales; así, la Fiscalía General de la Nación establece que la evidencia es cualquier objeto relacionado con una conducta punible que puede servir para determinar las circunstancias reales de tiempo, modo y lugar en las que el hecho se realizó y que deberá someterse al régimen de cadena de custodia. Mientras la prueba es considerada como aquel elemento que, una vez se hace parte de un proceso judicial, pretende hacer llegar al convencimiento acerca de la certeza de la existencia u ocurrencia de un determinado hecho (Ficalía, 2009) (Figura 4).

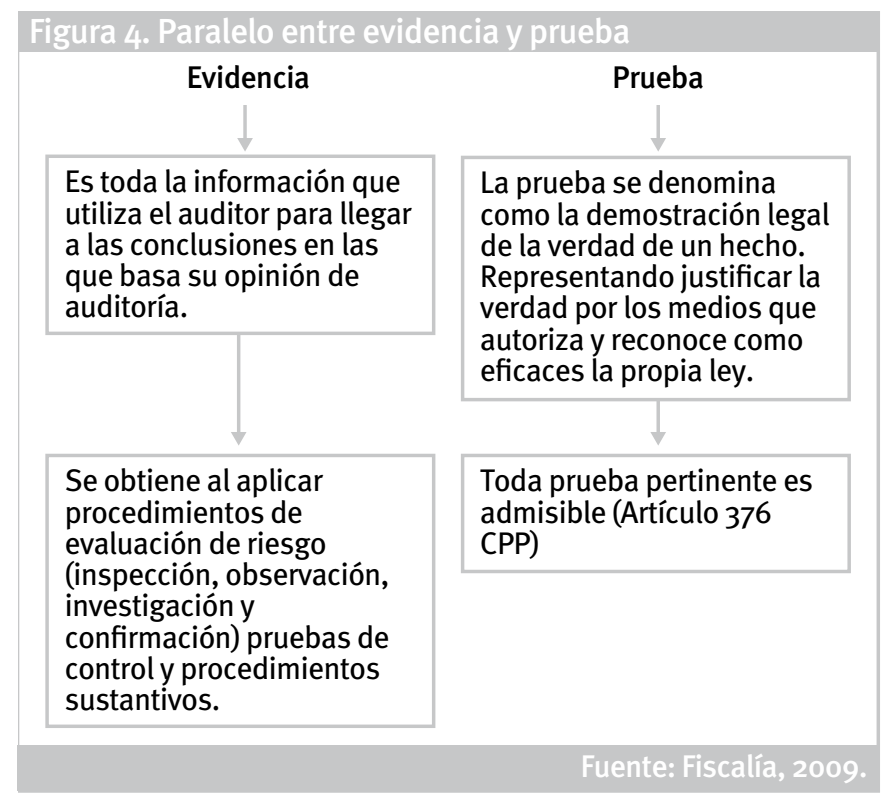

Una vez analizada la evidencia desde el punto de vista de la auditoría, la legislación colombiana contempla lo siguiente en el Código de Procedimiento Penal (CPP), en su Capítulo Tercero "Práctica de la prueba" (Figura 5):

a. La prueba tiene como fin llevar al conocimiento del juez, más allá de duda razonable, los hechos y circunstancias materia del juicio y los de la responsabilidad penal del acusado, como autor o partícipe (Artículo 372 (PP).

b. Los hechos y circunstancias de interés para la solución correcta del caso, se podrán probar por cualquiera de los medios establecidos en este código o por cualquier otro medio técnico o científico, que no viole los derechos humanos (Artículo 373 CPP).

c. El elemento material probatorio, la evidencia física y el medio de prueba se deberán referir, directa o indirectamente, a los hechos o circunstancias relativos a la comisión de la conducta delictiva y sus consecuencias, así como, a la identidad o a la responsabilidad penal del acusado. También es pertinente cuando sólo sirve para hacer más probable o menos probable uno de los hechos o circunstancias mencionados, o se refiere a la credibilidad de un testigo o de un perito (Artículo 375 CPP).

d. Toda prueba pertinente es admisible (Artículo 376 (PP), salvo en alguno de los siguientes casos:

* Que exista peligro de causar grave perjuicio indebido.

* Probabilidad de que genere confusión en lugar de mayor claridad al asunto, o exhiba escaso valor probatorio.

* Que sea injustamente dilatoria del procedimiento. e. Para condenar se requiere el conocimiento más allá de toda duda acerca del delito y de la responsabilidad penal del acusado, fundado en las pruebas debatidas en el juicio. La sentencia condenatoria no podrá fundamentarse exclusivamente en pruebas de referencia (Artículo 381 (PP). 
f. Los medios de conocimiento son la prueba testimonial, la prueba pericial, la prueba documental, la prueba de inspección, los elementos materiales probatorios, la evidencia física, o cualquier otro medio técnico o científico, que no viole el ordenamiento jurídico (Artículo 382 CPP).

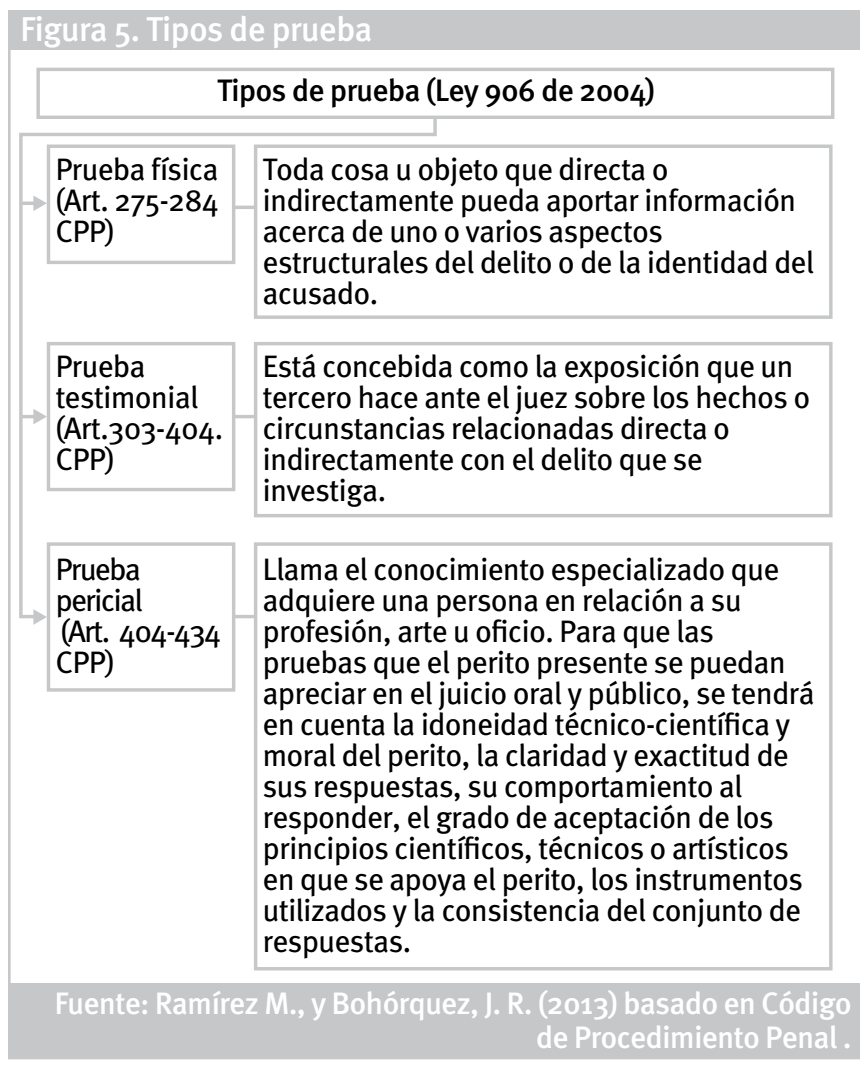

Etapa 3. Cadena de custodia de la documentación

La Ley 906 de 2004 (Art. 254- 266 CPP) señala que para demostrar la autenticidad de los elementos materiales probatorios y la evidencia física se dará uso a la cadena de custodia; este proceso que garantiza la veracidad de la información recolectada, se inicia en el lugar o sitio donde fueron hallados los elementos de prueba seguido del embalaje-envío, y finalizando por orden de la autoridad competente quien se encargará de certificar la cadena de custodia (Figura 6).

De igual manera la certificación se hace necesaria en este proceso porque es la afirmación de que el elemento hallado en el lugar, fecha y hora indicados en el rótulo, es el que fue recogido por la policía judicial y que ha llegado al laboratorio y ha sido examinado por el perito o peritos (Congreso de la República, 2004).

Etapa cuarta. Evaluación de evidencias e indicios. NIA 520 (IFAC, 2009)

La norma provee guías para la aplicación de procedimientos de revisión analítica en las etapas de planeación, recopilación de elementos de juicio, es decir como pruebas sustantivas y a la finalización de la auditoría como una revisión global.

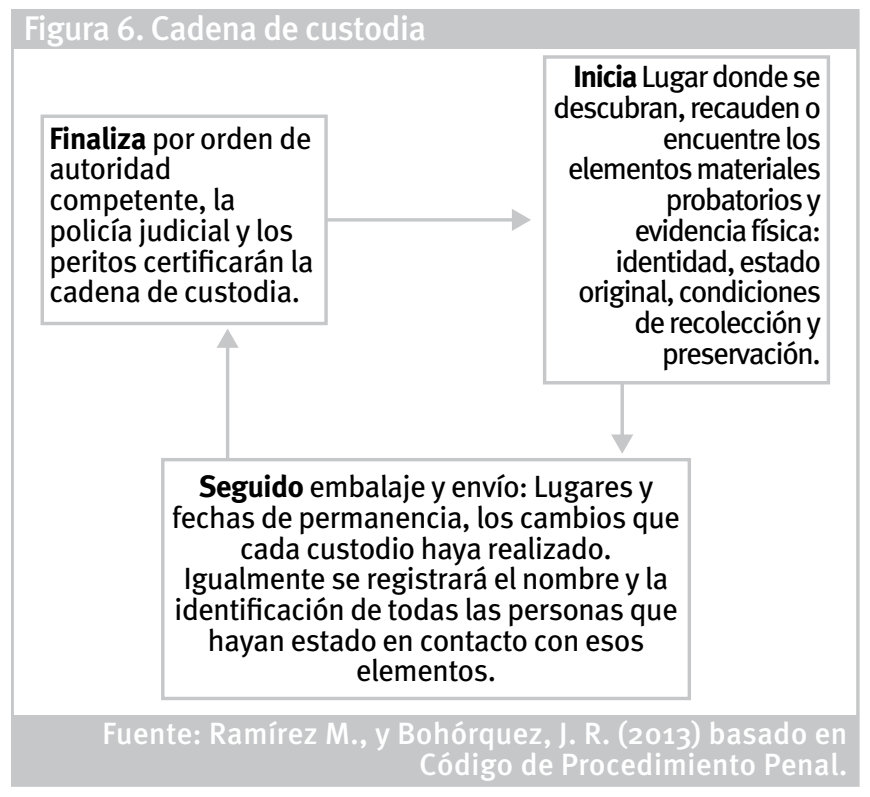

A su vez, proporciona detalles sobre las diferentes pruebas analíticas por ejecutar y el alcance de la confianza que ellas proveen de acuerdo con un conjunto de factores indicados en la norma.

Procedimientos analíticos sustantivos. La NIA 520 define los "procedimientos analíticos" como las evaluaciones de información financiera, por medio del análisis de las relaciones razonables entre datos financieros y no financieros.

Asimismo, la NIA 520 señala que los procedimientos analíticos también incluyen la investigación que sea necesaria sobre variaciones o relaciones identificadas que sean inconsistentes con otra información relevante, o que difieran de manera significativa de los valores esperados. Por lo anterior, la aplicación de estos procedimientos no termina con la evaluación, sino que implica la investigación sobre conclusiones inconsistentes con la expectativa del auditor.

Respecto a los procedimientos sustantivos de auditoría a nivel de aseveración estos pueden ser:

* Pruebas de detalles.

* Procedimientos analíticos sustantivos.

* Una combinación de ambos.

La decisión del auditor sobre qué procedimientos debería utilizar dependerá, según su juicio profesional, de su expectativa de efectividad y eficiencia de los procedimientos disponibles. Es decir, no hay una "receta secreta" sobre qué procedimientos utilizar y de qué tipo. Esto dependerá de qué tan efectivo y eficiente sea el procedimiento (que proporcione evidencia de auditoría y fácil de aplicar); es decir, que se logre cumplir con los objetivos de la auditoría, de la manera más rápida y eficiente.

Los aspectos a tener en cuenta al diseñar y ejecutar los procedimientos analíticos aparecen en la Figura 7. 


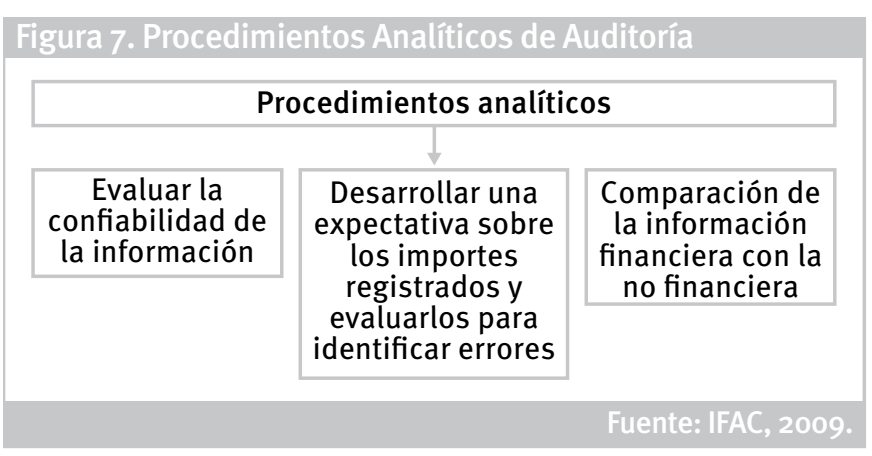

Cabe señalar que la efectividad de los procedimientos analíticos sustantivos no implica que estos se deban referir a modelos sofisticados; existen modelos sencillos capaces de proporcionar evidencia efectiva de auditoría. Ahora bien, respecto al oficio de la peritación este requiere de un proceso donde se certifique y verifique la idoneidad del trabajo efectuado en la realización de una investigación delincuencial, por lo que el CPP colombiano ha establecido (Figura 8).

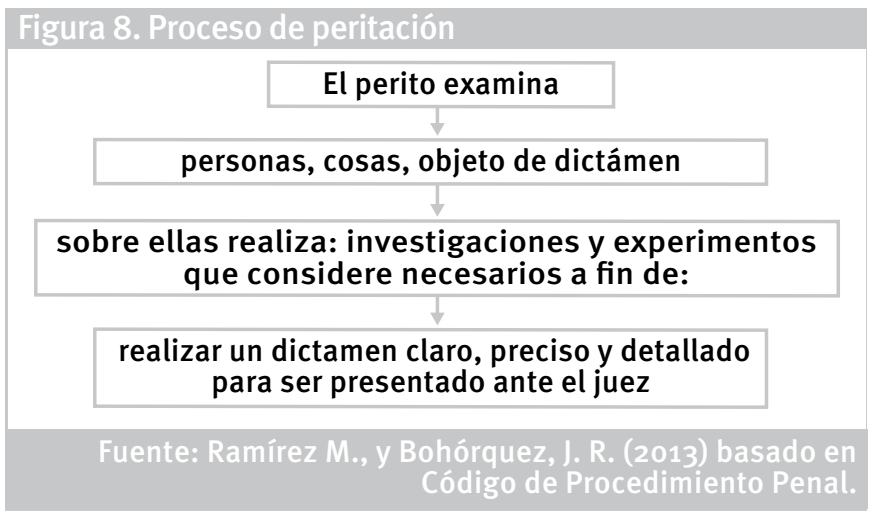

Para que la justicia pueda impartir una acusación sobre un hecho, esta debe evaluar y analizar lo concerniente al elemento material probatorio que se presenta o que se pretende hacer valer en un juicio, con el fin de proceder a la evaluación del cumplimiento de los principios de legalidad, pertinencia, autenticidad y aducción los cuales establecerán el grado de veracidad y afirmación de la verdad de los hechos, con los que se procederá a la acusación de que la conducta delictiva existió y que el imputado es su autor o partícipe (Congreso de la República, 2004).

Para que el hallazgo del material probatorio cuente con la validez legal mínima requerida es necesario que se cumplan los requisitos que aparecen en la Figura 9 (Congreso de la República, 2004).

Quinta Etapa. Elaboración del Informe de Auditoría Forense. NIA 700

El dictamen debe ser claro, preciso y detallado; en él se explicarán los exámenes, experimentos e investigaciones efectuadas. La NIA 700 solo puede ser utilizada para auditoría de estados financieros de propósito general. El propósito de esta NIA es establecer guías y proporcionar lineamientos sobre la forma y contenido del dictamen del auditor, emitido como resultado de una auditoría practicada por un auditor independiente de los estados financieros de una entidad (IFAC, 2009).

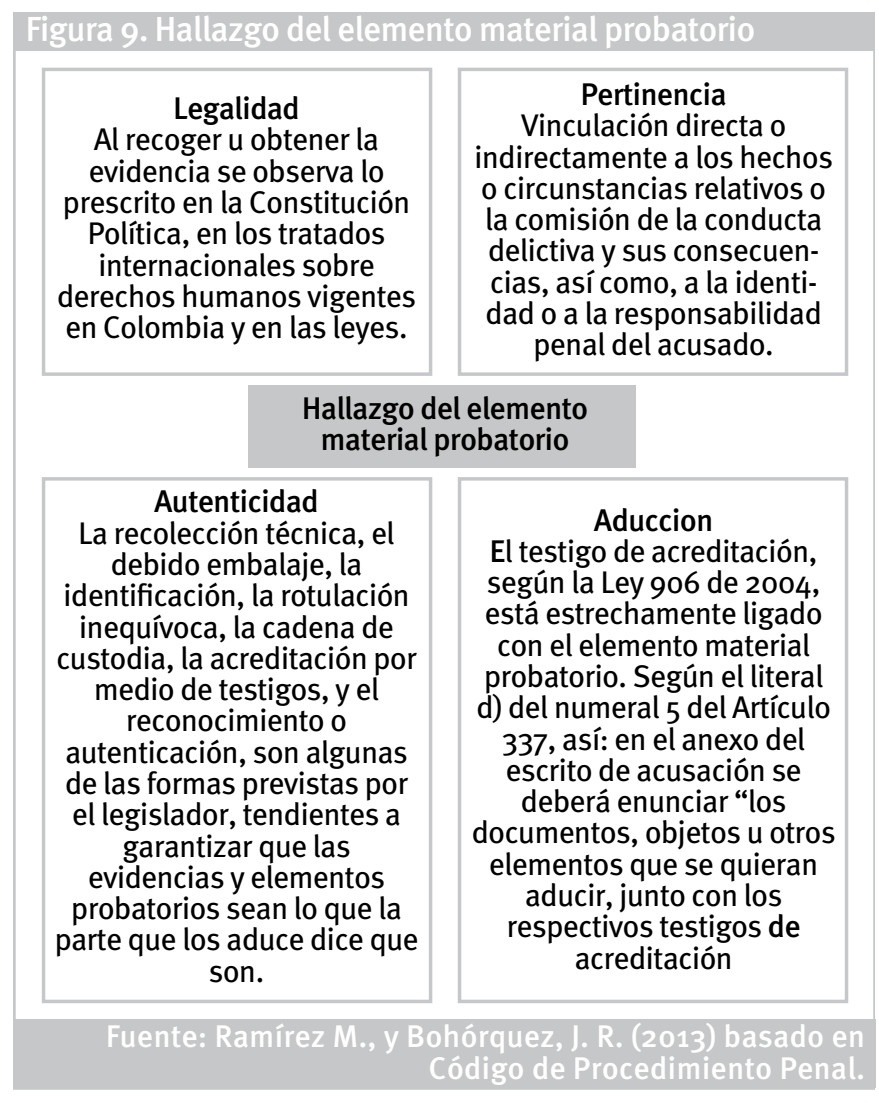

El auditor deberá analizar y evaluar las conclusiones extraídas de la evidencia de auditoría obtenida como base para la expresión de una opinión sobre los estados financieros, análisis y evaluación e incluye considerar si los estados financieros han sido preparados de acuerdo con un marco de referencia aceptable.

La formación de una opinión sobre los estados financieros implica analizar si la evaluación contiene políticas contables aplicadas en forma consistente de acuerdo con las circunstancias y evaluaciones de esta información su relevancia, confiabilidad, comprensibilidad y comparabilidad.

El dictamen emitido por el auditor debe contar con elementos básicos para su presentación con el propósito de garantizar cumplimiento normativo y calidad de la información puesta a consideración, por lo tanto, debe contener (Mejía y Montilla, 2007):

Un título apropiado. Indicar en forma precisa qué corresponde a un auditor independiente.

Destinatario. Debe dirigirse a las instancias correspondientes, de acuerdo con los requerimientos del trabajo.

Entrada o párrafo introductorio. Debe contener la identificación de la empresa y mencionar la información auditada.

Párrafo de alcance. El dictamen del auditor deberá describir el alcance de la auditoría declarando que fue conducida de acuerdo con normas internacionales de auditoría.

Responsabilidad del auditor. Debe expresar claramente que la responsabilidad del auditor es emitir una opinión sobre los estados financieros basados en una auditoría. 
Opinión del auditor. Expresar una opinión calificada cuando se determina que la información financiera se presenta de forma razonable respecto al marco de referencia aplicable.

Firma de auditor. Todo dictamen debe firmarse, a nombre propio y/o a nombre de la firma de auditoría según el caso.

Fecha del dictamen. El auditor deberá fechar su dictamen el día de terminación de la auditoría.

Dirección del auditor. Debe mencionar el país y la dirección completa del sitio donde el auditor ejerce.

Como la responsabilidad del auditor es dictaminar sobre los estados financieros, según fueron preparados y presentados por la administración, el auditor no deberá fechar el dictamen antes de la fecha en que los estados financieros sean firmados 0 aprobados por la administración. De igual forma existen aspectos que implican modificación del dictamen del auditor como pueden ser las limitaciones al alcance del trabajo y desacuerdos con la administración (IFAC, 2009).

El auditor deberá analizar y evaluar las conclusiones extraídas de la evidencia de auditoría obtenida como base para la expresión de una opinión sobre los estados financieros. Este análisis y evaluación incluye considerar si los estados financieros han sido preparados de acuerdo con un marco de referencia aceptable.

Formación de una opinión sobre los estados financieros implica analizar si la evaluación contiene políticas contables aplicadas en forma consistente de acuerdo con las circunstancias y evaluaciones de la información si es relevante, confiable, entendible y comparable.

Toda declaración que realice un perito debe estar procedida por un informe pericial el cual expresará la base de opinión utilizada y que mediante este dará a conocer en juicio público, de forma escrita la investigación realizada y los demás hechos o circunstancias que permitieron o limitaron el esclarecimiento de la verdad (Figura 10).

El informe o dictamen pericial permite demostrar ante la justicia por medios escritos y/o documentales una conclusión sobre la verdad de un ilícito que lleva a esta a declarar la culpabilidad o inocencia del acusado. Los peritos realizarán el estudio acucioso, riguroso del problema encomendado para producir una explicación consistente; esa actividad cognoscitiva será condensada en un documento que refleje las secuencias fundamentales del estudio efectuado, los métodos y medios importantes empleados, una exposición razonada y coherente, las conclusiones, fecha y firma.

A ese documento se le conoce generalmente con el nombre de dictamen pericial o informe pericial. Si los peritos no concuerdan deberá nombrarse un tercero para dirimir la discordia, quién puede disentir de sus colegas (Congreso de la República, 2004).

Todo dictamen pericial debe contener (Congreso de la República, 2012):

a. La descripción de la persona, objeto o cosa materia de examen o estudio, así como, el estado y forma en que se encontraba.

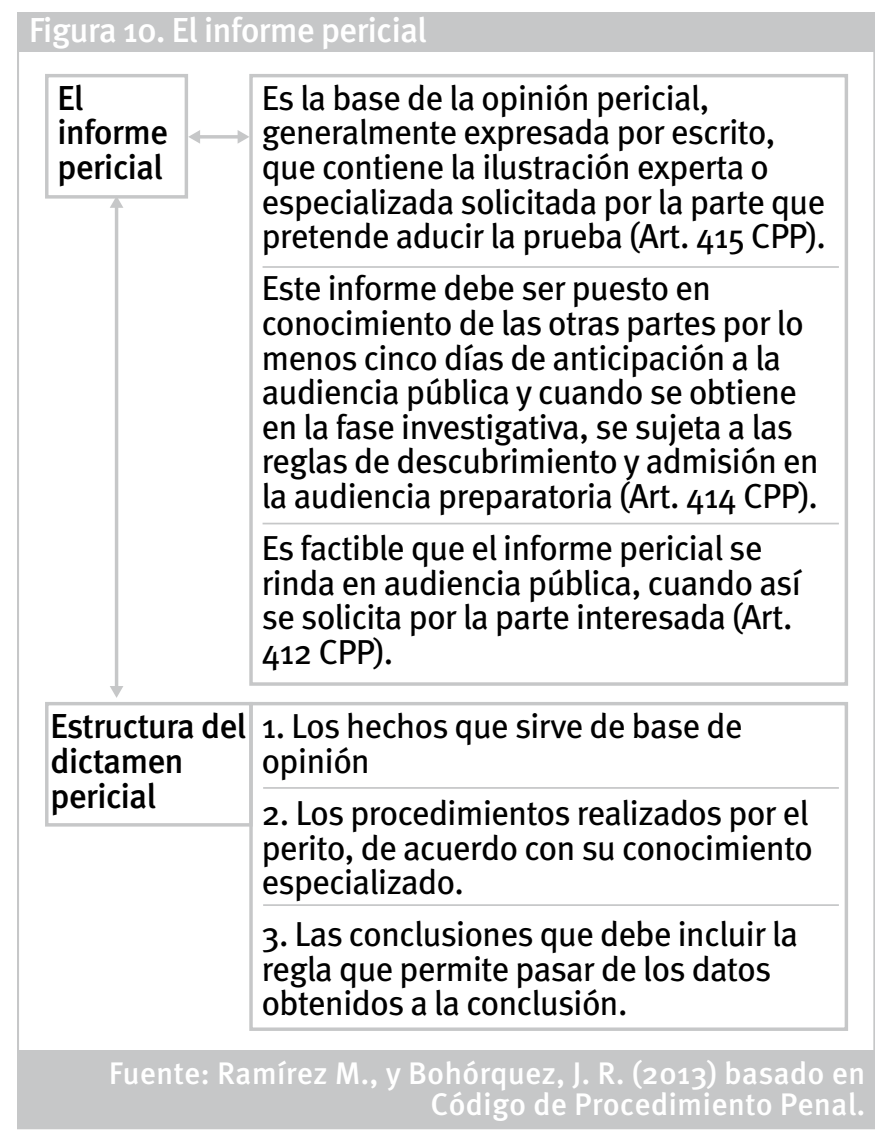

b. La relación detallada de todas las operaciones practicadas en la pericia y su resultado.

c. Los medios científicos o técnicos de que se han valido para emitir su dictamen.

d. Las conclusiones a las que llegan el (los) perito (s).

Al apreciar el dictamen se tendrá en cuenta la firmeza, precisión y calidad de sus fundamentos, la competencia de los peritos y los demás elementos probatorios que obren en el proceso. Si se hubiere practicado un segundo dictamen, este no sustituirá al primero pero se estimará conjuntamente con él, excepto cuando prospere objeción por error grave.

Tercera fase: comunicación de resultados

La comunicación de resultados será permanente con los funcionarios que el auditor forense estime pertinente.

Al comunicar resultados parciales o finales el auditor debe ser cauto, prudente, estratégico y oportuno, limitarse a informar lo que fuere pertinente, un error en la comunicación de resultados puede arruinar toda la investigación (muchas veces se filtra información o se alerta antes de tiempo a los investigados de los avances obtenidos). Los informes deben contener los antecedentes del caso en cuestión, descripción de los procedimientos llevados a cabo, descripción del alcance del trabajo, así como, de las limitaciones que se hayan presentado, análisis y explicación de las pruebas obtenidas y conjuntamente con su opinión el auditor forense debe detallar las recomendaciones a seguir. 
Los dictámenes de los auditores forenses se deben basar exclusivamente en las pruebas que obtuvieron durante el trabajo de campo, cumpliendo con las normas internacionales de auditoría para su presentación y exposición.

Los informes deben contener los antecedentes del caso en cuestión, descripción de los procedimientos llevados a cabo y del alcance del trabajo, así como, de las limitaciones que se hayan presentado, análisis y explicación de las pruebas obtenidas y conjuntamente con su opinión el auditor forense debe detallar las recomendaciones a seguir.

\section{Presentación del informe técnico}

Para apreciar la prueba pericial, en el juicio oral y público, se tendrá en cuenta la claridad y exactitud de las respuestas de cada uno de los terceros llamados a rendir declaratoria ante el tribunal (Congreso de la República, 2004).

\section{Cuarta fase. Seguimiento y monitoreo del caso}

Monitoreo permanente

Esta última fase tiene por finalidad asegurar que los resultados de la investigación forense sean considerados según fuere pertinente y evitar que queden en el olvido, otorgando a los perpetradores del fraude la impunidad.

Registro y revisión de antecedentes

Una investigación de antecedentes puede identificar información de valor actual, valor histórico u otra información relevante que sea de interés para el especialista forense. Esta información puede incluir tanto registros de propiedad de inmuebles como activos personales, registros de negocios o sociedades, registros comerciales, criminales, y hasta operaciones bursátiles de la gerencia o directores de las compañías.

Mediante la revisión de estos registros de carácter público el investigador forense podría llegar a comprender las motivaciones posibles y los incentivos o presiones para ejecutar un fraude. Por ejemplo, el especialista forense puede llegar a descubrir actividades bursátiles del tipo insider trading, que ponen en ventaja a un inversionista que cuenta con información clave en el momento oportuno y la aprovecha, transacciones con partes relacionadas, negocios que sean de propiedad o controlados por individuos bajo investigación, o que pudieran sugerir la existencia de conflictos de intereses.

\section{Recomendaciones}

La auditoría forense es una auditoría especializada en allegar la prueba pericial contable especializada ante los tribunales judiciales.

Las normas internacionales de auditoría aportan a la auditoría forense aspectos como la importancia relativa, el riesgo probable y brindan una perspectiva mayor de cómo el delincuente puede llegar a cometer un fraude contable con la información financiera existente.
Caracterizar la evidencia desde el punto de vista de la auditoría implica establecer procedimientos que proporcionen guías suficientes y pertinentes sobre lo que constituye evidencia.

Con la determinación de los elementos necesarios, suficientes y esenciales de validez de la prueba pericial contable especializada se forma una nueva base jurídica que describirá los elementos legales que forman parte de esta actividad los cuales son mecanismos legislativos que evaluaran la integridad, veracidad, idoneidad de la evidencia, y mediante estos aspectos se propenderá por el esclarecimiento de la verdad la cual define la calidad del trabajo del auditor forense.

La metodología establecida en la presente investigación consiste en plantear un proceso general para el desarrollo de una auditoría forense porque cada clase de fraude contable requiere la ampliación, adición o simplificación de algunos de los procedimientos mencionados.

Los procedimientos utilizados son de carácter general porque es el auditor quien utiliza su criterio profesional para la aplicación de estos y según la planeación y el caso investigado pueden variar y llegar a ser distintos a los aquí citados.

La información que se muestra en este documento recopila datos y técnicas jurídicas, de auditoría y de investigación criminal que convergen con el propósito de apoyar al perito en la búsqueda de la autenticidad del fraude contable con el objetivo de que el contador público sea garante de la verdad ante la justicia.

\section{Referencias}

Bermúdez, J. M. (2000). Control, auditoría y revisoría fiscal. Bogotá, Colombia: Ecoe Ediciones.

Cano, M. A. (2000). Prácticas contables para determinar el lavado de dinero. Bogotá, Colombia: G\&D Impresores.

Cano, M. A., \& Lugo, D. (2005). Auditoría forense en la investigación criminal del lavado de dinero y activos. Bogotá, Colombia: Ecoe Ediciones.

Cano, M. A., \& Lugo, D. (2009). Auditoría forense en la investigación criminal del lavado de dinero y activos. Bogotá, Colombia: Ecoe Ediciones.

Chavarria, J., \& Roldán, M. (1996). Auditoria forense. San Jose, Costa Rica: Universidad Estatal a Distancia.

Congreso de la República de Colombia. (1990). Ley 43 de 1990. Bogotá.

Congreso de la República de Colombia. (2004). Código de Procedimiento Penal. Bogotá.

Congreso de la República de Colombia. (2004). Ley 906 de 2004. Bogotá.

Congreso de la República de Colombia. (2004). Ley 906 de 2004 (Art. 273). Bogotá.

Congreso de la República de Colombia. (2004). Ley 906 de 2004 (Art.420). Bogotá.

Congreso de la República de Colombia (2004). Ley 906 de 2004 (Art 212-215). Bogotá.

Congreso de la República de Colombia (2012). Código de Procedimiento Civil (Art. 241). Bogotá. 
Congreso de la República. (2012) de Colombia. Código de Procedimiento Civil Ley 564. Bogotá.

Congreso de la República de Colombia. (2013). Régimen Contable Colombiano. Bogotá, Colombia: Legis.

Danilo, C. D. (2009). Auditoría financiera forense. Bogota, Colombia: Ecoe Ediciones.

Estupiñan, R. (2006). Control interno y fraude con base en los ciclos transaccionales. Bogotá, Colombia: ROESGA.

Federación Internacional de Contadores. (2009a). Norma Internacional de Auditoría 240. New York, Estados Unidos: IFAC.

Federación Internacional de Contadores. (2009b). Norma Internacional de Auditoría 300. New York, Estados Unidos: IFAC.

Federación Internacional de Contadores, (2009c). Norma Internacional de Auditoría 320. New York, Estados Unidos: IFAC.

Federación Internacional de Contadores, (2009d). Norma Internacional de Auditoría 450. New York, Estados Unidos: IFAC.

Federación Internacional de Contadores, (2009e). Norma Internacional de Auditoría 50o. New York, Estados Unidos: IFAC.

Federación Internacional de Contadores, (2009f). Norma Internacional de Auditoría 520. New York, Estados Unidos: IFAC.

Federación Internacional de Contadores, (2009g). Norma Internacional de Auditoría 70o. New York, Estados Unidos: IFAC.
Fontán, E. (2009). El impacto de la auditoría forense como técnica en la detección, prevención y control del fraude. Buenos Aires, Argentina: Instituto de auditores forenses IDEAF (pp.1-9)

Cardenas, L. M., \& Becerra, A. M. (2010). Rol del contador auditor, en la aplicación de la justicia.Recuperado de http://www.interamericanusa.com/articulos/Auditoria/ Rol-Cont-1.htm

Kranacher, M.J., \& Riley, R. (1952). Forensic accounting and fraud examination. Hoboken, USA: Wiley.

Mejía, E., \& Montilla, O. (2007). Estándares internacionales de contabilidad en Colombia. Bogotá, Colombia: Universidad Libre.

Nación, Fiscalia General. (2009). Prueba Pericial. Bogotá, Colombia: Fiscalía General de la Nación.

Rodríguez Castro, B. (2009). Una aproximación a la auditoría forense. Bogotá, Colombia: Universidad Javeriana.

Saccani, R. (2010). Tratado de auditoría forense. La investigación y prueba de los delitos de cuello blanco. Buenos Aires, Argentina: KPMG.

Singleton, A. J., Bologna, G. J., \& Lindquist, R. J. (2006). Fraud auditing and forensic accounting. Hoboken, USA: Wiley.

Cuadernos de Administración / Facultad de Ciencias de la Administración / Universidad del Valle Periodicidad: semestral / ISSN impreso Nº120-4645 - ISSN electrónico N²256-5078 / Nombre abreviado: cuad.adm. Edición Vol. $29 \mathrm{~N}^{\circ} 50$ (julio - diciembre de 2013)

Metodología y desarrollo de la auditoría forense en la detección del fraude contable en Colombia / Johana Reina Bohórquez y Maricela Ramírez

\section{(c) (i) (3) (-)}

Revista Cuadernos de Administración por Universidad del Valle se encuentra bajo una Licencia Creative Commons Atribución-NoComercialCompartirlgual 2.5 Colombia.

Basada en una obra en http://cuadernosadm.univalle.edu.co. 